\title{
The Female Athlete's Heart: Facts and Fallacies
}

\author{
Clea Simone S. S. Colombo, MD ${ }^{1,2, *}$ \\ Gherardo Finocchiaro, $M D^{3}$
}

\author{
Address \\ ${ }^{*}, 1$ MSc Sports Cardiology, Cardiology Clinical Academic Group, St George's Univer- \\ sity of London, Cranmer Terrace, SW 17 ORE, London, UK \\ Email: cleacolombo@gmail.com \\ ${ }^{2}$ Cuore Dello Sport, Valinhos, R. Luiz Spiandorelli Neto, 60, s307. Valinhos, São \\ Paulo, Brazil \\ ${ }^{3}$ Cardiology Clinical Academic Group, St George's University of London, Cranmer \\ Terrace, SW 17 ORE, London, UK
}

Published online: 3 November 2018

(C) The Author(s) 2018

This article is part of the Topical Collection on Sports Cardiology

Keywords Female athletes · Cardiac remodeling · Sudden cardiac death

Abbreviations $A F$ atrial fibrillation - ARVC arrhythmogenic right ventricular cardiomyopathy - CAC coronary artery calcification - CAD coronary artery disease - CMR cardiac magnetic resonance - DHT dihydrotestosterone - HCM hypertrophic cardiomyopathy - LV left ventricular - LVEDD left ventricular end diastolic diameter - LVH left ventricular hypertrophy - LVM left ventricular mass - LVWT left ventricular wall thickness $\cdot R V$ right ventricle $\cdot R W T$ relative wall thickness $\cdot S C D$ sudden cardiac death $\cdot$ TWI T wave inversion

\begin{abstract}
Purpose of the review For many years, competitive sport has been dominated by men. Recent times have witnessed a significant increase in women participating in elite sports. As most studies investigated male athletes, with few reports on female counterparts, it is crucial to have a better understanding on physiological cardiac adaptation to exercise in female athletes, to distinguish normal phenotypes from potentially fatal cardiac diseases. This review reports on cardiac adaptation to exercise in females.

Recent findings Recent studies show that electrical, structural, and functional cardiac changes due to physiological adaptation to exercise differ in male and female athletes. Women tend to exhibit eccentric hypertrophy, and while concentric hypertrophy or concentric remodeling may be a normal finding in male athletes, it should be evaluated carefully in female athletes as it may be a sign of pathology. Although few studies on veteran female athletes are available, women seem to be affected by atrial fibrillation, coronary atherosclerosis, and myocardial fibrosis less than male counterparts.

Summary Males and females exhibit many biological, anatomical, and hormonal
\end{abstract}


differences, and cardiac adaptation to exercise is no exception. The increasing participation of women in sports should stimulate the scientific community to develop large, longitudinal studies aimed at a better understanding of cardiac adaptation to exercise in female athletes.

\section{Introduction}

Regular intensive exercise leads to a series of electrical, structural, and functional changes in the heart, collectively named as the "athlete's heart" [1]. Most of the studies on cardiac adaptation to exercise have investigated male athletes. Until the first half of the twentieth century, women were discouraged from practicing sport at a competitive level because females were thought to be physiologically unable to perform at high standards, and it was believed that intense exercise could lead to female infertility [2]. Women's participation in competitive sports has progressively increased since the 1980s, and the proportion of females among marathon runners has increased from $10 \%$ in
1980 to $43 \%$ in 2013 [3]. Females comprised almost half of the athletes participating in the Olympic Games in Rio de Janeiro in 2016 [4].

Although the recent years have witnessed an increasing participation of women in competitive sport activities, data on cardiac adaptation in female athletes are limited. Recent studies showed important gender differences in patterns of electrical and structural cardiac adaptations $[5 \bullet, 6 \bullet \bullet$. Incidence of sudden cardiac death (SCD) in sports is significantly lower in female athletes (male/female ratio is 10:1), and it is possible that gender-related differences in cardiac adaptation to exercise may offer some explanation [7].

\section{The athlete's heart}

Regular intense exercise training promotes electrical, structural, and functional cardiac changes which are influenced by age, sex, body size, ethnicity, and sport discipline [8]. Physiological cardiac adaptation usually results in symmetrical enlargement of all cardiac chambers and increased vagal tone, with typical ECG changes as sinus bradycardia, AV blocks, and voltage criteria for right and left ventricular hypertrophy. Early repolarization is commonly observed in athletes and anterior T wave inversion (TWI) may be found, especially in individuals of Afro-Caribbean descent. Cardiac remodeling may be marked in some athletes, resulting to significant overlap with potentially fatal cardiac disease such as cardiomyopathies [1].

Highly trained athletes exhibit an increase in left and right ventricular size of $10-15 \%$ when compared with sedentary individuals. In Olympic athletes, left ventricular (LV) size has been shown to be higher than the upper limits of normal (LV end-diastolic diameter $>54 \mathrm{~mm}$ ) in almost half of the cases. In some athletes, especially those engaged in high dynamic modalities, such as rowing, cross-country, and cycling, the LV end-diastolic diameter may exceed $60 \mathrm{~mm}$ [9]. The LV wall thickness may be mildly increased in white athletes, but rarely exceeds $12 \mathrm{~mm}$ [10] whereas athletes of Afro-Caribbean descent exhibit increased wall thickness $(>12 \mathrm{~mm})$ in up to $18 \%$ of the cases [11]. Although LV systolic function is usually within conventional normal limits in athletes, endurance athletes may exhibit mildly reduced LV ejection 
fraction $(<50 \%)$ at rest, with significant contractility recruitment during exercise $[12,13]$.

Similar to the LV, the right ventricle (RV) also enlarges in athletes. Zaidi et al. showed that at echocardiography, $61 \%$ of male and $46 \%$ of female athletes exhibit RV dimensions that fulfill the minor diagnostic criterion for arrhythmogenic right ventricular cardiomyopathy (ARVC) [14].

\section{Cardiac adaptation to exercise in female athletes}

Although cardiac physiological adaptation may be qualitatively similar in male and female athletes, on average women are smaller, have lower lean body mass, and a different hormonal profile than men with significant impact on cardiac dimensions [15]. In addition, sympathetic adrenergic response during exercise as well as peak systolic blood pressure, stroke volume, and peak VO2 during exercise may be lower in female athletes $[16,17]$. These differences may impact significantly on cardiac structural changes resulting from intense training.

Highly trained athletes often exhibit ECG patterns, which are reflective of physiological adaptations to exercise and may in some cases overlap with conditions predisposing to sudden cardiac death (SCD). The differential diagnosis between physiology and pathology may be challenging, and therefore, a good understanding of what constitutes a normal ECG in specific athletic sub-groups is necessary. The recently published International recommendations for ECG interpretation in athletes provide a thorough guidance for the interpretation of the athlete's ECG, specifying what type of ECG abnormalities would require further investigations to rule out pathology $[18 \bullet]$. However, this document is predominantly based on studies of male athletes. Recent studies show that sex has a significant effect on ECG patterns in athletes. Finocchiaro et al. [6••] showed that Sokolow-Lyon (SL) voltage criteria for left ventricular hypertrophy (LVH) as well as left axis deviation are less common in female than in male elite athletes in a study including more than 1000 highly trained athletes. The SL criteria for LVH were present in $14 \%$ of females compared with $42 \%$ of males, while left axis deviation was present in $0.4 \%$ of females compared with $4 \%$ of males. Conversely, anterior T wave inversion (TWI) was more

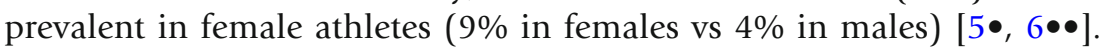
These findings were confirmed by the study by Malhotra et al. [5•], where anterior TWI were found in $6.5 \%$ of female athletes and in $2.1 \%$ of male athletes. The combination of J point elevation $>0.1 \mathrm{mV}$ in V1-V2 and anterior TWI may be observed in male athletes, especially of AfroCaribbean origin, and this feature is regarded as a sign of physiological adaptation to exercise [19]. However, this ECG sign is rarely observed in highly trained female athletes, and its absence should not be considered as suggestive of pathology [20] (Fig. 1). 


\section{a}

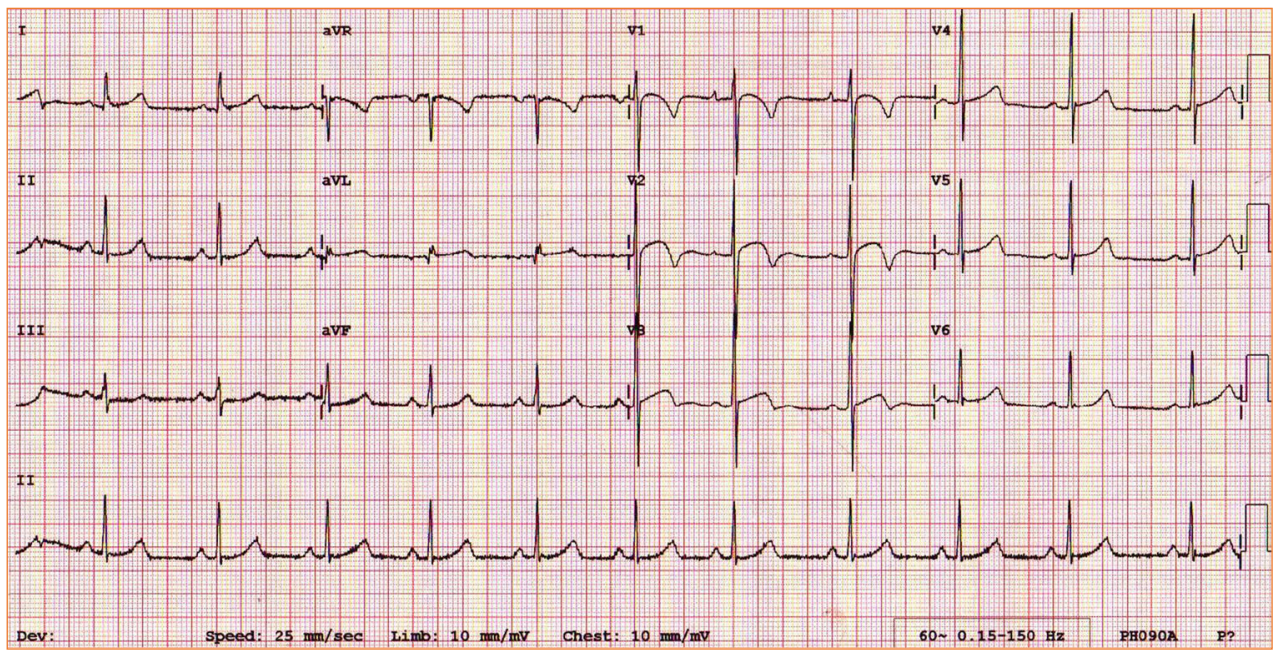

b

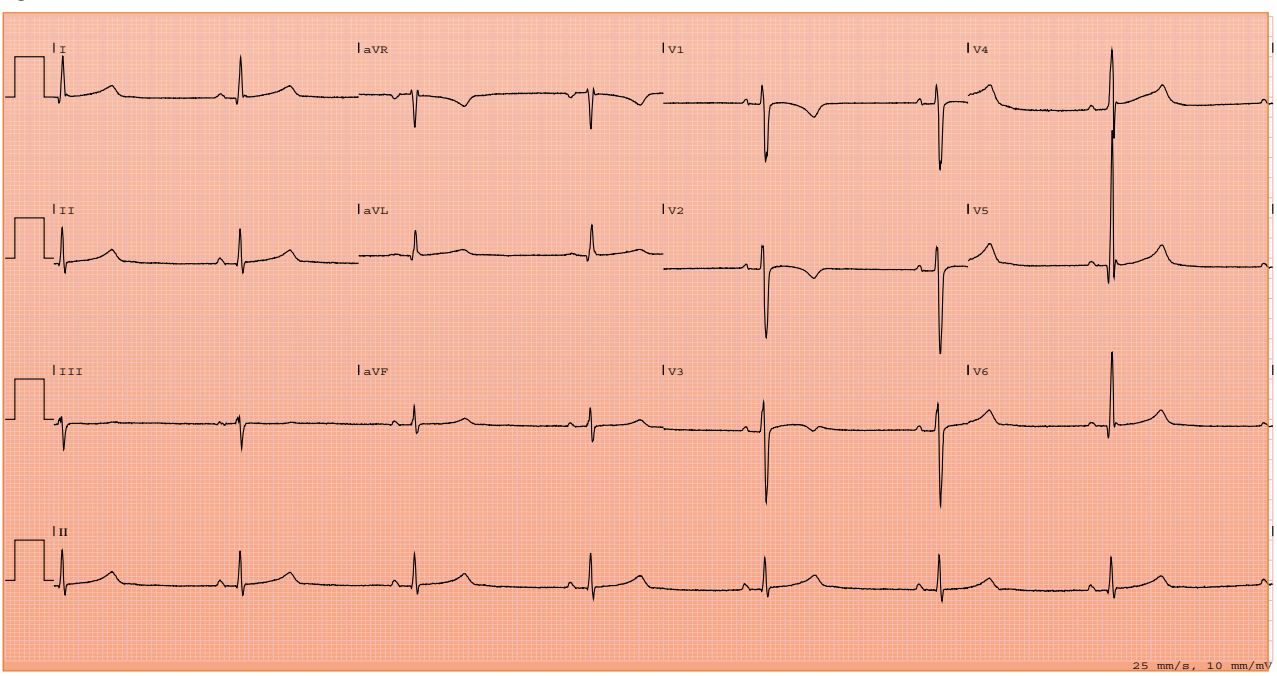

Fig. 1. ECG patterns in male (a) and female (b) athletes. Note the combination of anterior T wave inversion and significant (> $0.1 \mathrm{mV}$ ) J point elevation and the voltage criteria for LVH in the male athlete's ECG. Conversely, the female athlete's ECG is characterized by the absence of $\mathrm{J}$ point elevation and voltage criteria for LVH.

On the largest study on black female athletes, Rawlins et al. [21] showed that female athletes of Afro-Caribbean descent exhibit more frequently anterior TWI than white counterparts.

In male athletes, cardiac adaptation to exercise results in structural remodeling of both ventricles and atria. As body size differs between males and females, absolute cardiac dimensions are lower in females reflecting the different an-

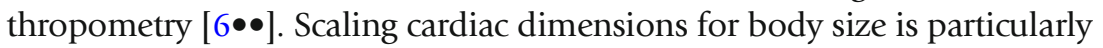
relevant in this context, in order to have a more accurate appreciation of the degree of cardiac remodeling. 


\section{Left ventricle}

On a large cohort $(n=600)$ of elite female athletes, Pelliccia et al. [22] showed that an LV end-diastolic diameter (LVEDD) $>54 \mathrm{~mm}$, consistent with a diagnosis of dilated cardiomyopathy (DCM), was present in $8 \%$ of athletes. Maximal LV wall thickness was $14 \%$ greater in female athletes in comparison with sedentary counterparts, but $23 \%$ lower than male athletes. Importantly, none of the female athletes showed a LV wall thickness $>12 \mathrm{~mm}[22]$. Therefore, an enlarged left ventricle raising the suspicion of DCM or a wall thickness consistent with hypertrophic cardiomyopathy (HCM) is less common in female athletes than male counterparts. A female athlete showing an LV cavity exceeding $60 \mathrm{~mm}$ or a LV wall thickness $>12 \mathrm{~mm}$ should be further investigated to exclude

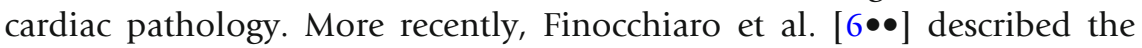
effect of sex and sport discipline on LV geometry in 1083 white elite athletes (41\% female athletes). Absolute LVEDD $>54 \mathrm{~mm}$ was observed only in $7 \%$ of female athletes and $\mathrm{LV}$ wall thickness was $\leq 12 \mathrm{~mm}$ in all females, confirming previous studies. Interestingly, LVEDD indexed for BSA was higher in female athletes (LVEDD $\geq 31 \mathrm{~mm} / \mathrm{m}^{2}$ in $18 \%$ of females vs $10 \%$ of males). In the specific subgroup of athletes engaged in dynamic exercise, females showed eccentric hypertrophy more frequently than males, while males showed more commonly concentric remodeling/hypertrophy. None of the female athletes demonstrated RWT $>0.48$ or $\operatorname{LVM}>145 \mathrm{~g} / \mathrm{m}^{2}[6 \bullet \bullet]$.

Rawlins et al. [21] compared 200 black female athletes with white female athletes of similar age, size, and type of sport and demonstrated that black female athletes exhibited a LV wall thickness $>11 \mathrm{~mm}$ in $3 \%$ of the cases compared with none of white female athletes. No female athlete exhibited a LV wall thickness $>13 \mathrm{~mm}$ [21]. These findings (Table 1 and Fig. 2) suggest that cardiac adaptation to exercise tends to be characterized by a more significant increase in chamber size rather than in wall thickness in females. The presence of concentric hypertrophy or concentric remodeling in female athletes should be evaluated carefully and may be suggestive of HCM in individuals with a family history of premature disease or with an abnormal ECG.

\section{Right ventricle}

Exercise-induced cardiac remodeling is not a prerogative of the left heart and the right heart is known to be very sensitive to volume loading conditions, especially in endurance athletes. Zaidi et al. [14] showed that although absolute RV dimensions are larger in male athletes compared with females, RV size indexed for BSA is higher in female than male athletes $[23,24]$. This is particularly relevant as RV enlargement may overlap with the pathological dilatation of the RV in patients with ARVC. Athletic training has several deleterious effects in terms of risk of arrhythmias and phenotype progression in patients with ARVC or even in carriers of desmosomal mutations, and therefore, the differential diagnosis is particularly relevant in athletes [25-27]. Echocardiographic evaluation of 
Table 1. Chamber dimensions at echocardiography in female athletes

\begin{tabular}{|c|c|c|c|}
\hline \multicolumn{4}{|c|}{ Left ventricle } \\
\hline & Pelliccia et al. 1996 & Rawlins et al. 2010 & Finocchiaro et al. 2016 \\
\hline Number ethnicity & 600 females White & 200 females Black & 438 females White \\
\hline LVWT > $12 \mathrm{~mm}$ & $0 \%$ & $2 \%$ & $0 \%$ \\
\hline LVEDD $>54 \mathrm{~mm}$ & $8 \%$ & $8 \%$ & $7 \%$ \\
\hline LVEDD index & $29.8 \pm 2.5 \mathrm{~mm} / \mathrm{m}^{2}$ & - & $28.6 \pm 2.7 \mathrm{~mm} / \mathrm{m}^{2}$ \\
\hline LVM index & $80 \pm 16 \mathrm{~g} / \mathrm{m}^{2}$ & - & $83 \pm 17 \mathrm{~g} / \mathrm{m}^{2}$ \\
\hline \multicolumn{4}{|c|}{ Left atrium } \\
\hline & Pelliccia et al. 1996 & Rawlins et al. 2010 & Iskandar et al. 2015 \\
\hline Number ethnicity & 600 females White & 200 females Black & 7018 athletes mixed \\
\hline LA diameter & $32.5 \pm 3.5 \mathrm{~mm}$ & $35.3 \pm 4.7 \mathrm{~mm}$ & $34.2 \mathrm{~mm}$ \\
\hline LA volume index & - & - & $30.9 \mathrm{ml} / \mathrm{m}^{2}$ \\
\hline \multicolumn{4}{|c|}{ Right ventricle and right atrium } \\
\hline & D'Ascenzi et al. 2017 & Zaidi et al. 2013 & D’Ascenzi et al. 2017 \\
\hline Number ethnicity & 363 females White & 57 females Black & 6806 athletes mixed \\
\hline RVOTP & $26.1 \pm 3.6 \mathrm{~mm}$ & $26.7 \pm 3.8 \mathrm{~mm}$ & $28 \pm 2.0 \mathrm{~mm}$ \\
\hline RV0T1 & $27.3 \pm 4.1 \mathrm{~mm}$ & $28.1 \pm 4.5 \mathrm{~mm}$ & $30 \pm 1.0 \mathrm{~mm}$ \\
\hline RVEDA & $19.3 \pm 3.9 \mathrm{~cm}^{2}$ & $21.6 \pm 3.8 \mathrm{~cm}^{2}$ & $23 \pm 0.1 \mathrm{~cm}^{2}$ \\
\hline RA area & $14.8 \pm 3.4 \mathrm{~cm}^{2}$ & $14.4 \pm 3.1 \mathrm{~cm}^{2}$ & $16 \pm 1.0 \mathrm{~cm}^{2}$ \\
\hline
\end{tabular}

the RV should not rely on size alone, but also on other features such as the presence of regional wall motion abnormalities or possible aneurysms in order to distinguish RV alterations typical of ARVC from those detected in athletes as a consequence of intensive physical activity $[28,29]$.

\section{Atria}

Left and right atrial enlargements are often observed in highly trained athletes. In a recent meta-analysis of 54 studies, Iskandar et al. [30] confirmed that athletes had greater LA size in comparison with controls with a 13\% increase in LA diameter and a 30\% increase in LA volume index. The mean LA diameter was $36 \mathrm{~mm}$ in male elite athletes and $34 \mathrm{~mm}$ in female elite athletes, and the mean diameter was $4.1 \mathrm{~mm}$ greater in comparison with sedentary controls [30]. Right atrial remodeling is particularly evident in endurance athletes, as a response to the prolonged increase in cardiac output [31-33]. Although most studies included male athletes, in order to standardize right cardiac measurements, Zaidi et al. [14] proposed an upper limit for RA area of $28 \mathrm{~cm}^{2}$ in male athletes and $24 \mathrm{~cm}^{2}$ in female athletes. Interestingly, these authors found no significant differences between black and white male athletes but greater RA dimensions in white female athletes. 


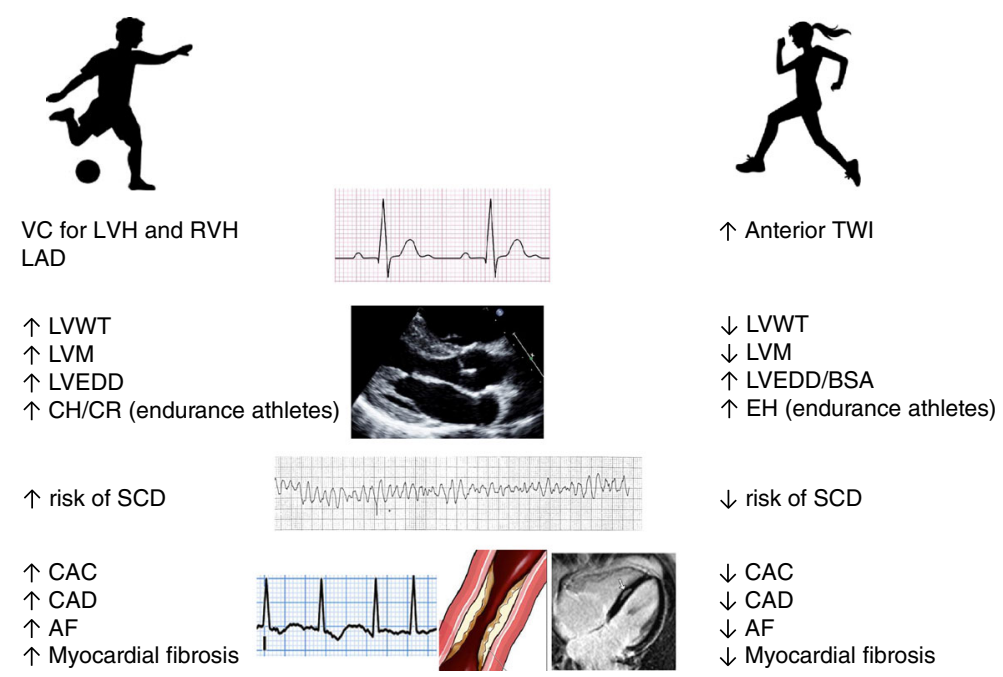

Fig. 2. Main gender differences in cardiac adaptation to exercise. Abbreviations: AF: atrial fibrillation; BSA: body surface area; CAC: coronary artery calcification; CAD: coronary artery disease; $\mathrm{CH}$ : concentric hypertrophy; $\mathrm{CR}$ : concentric remodeling; EH: eccentric hypertrophy; LAD: left atrial dilation; LVEDD: left ventricular end diastolic diameter; LVH: left ventricular hypertrophy; LVM: left ventricular mass; LVWT: left ventricular wall thickness; RVH: right ventricular hypertrophy; VC: voltage criteria.

\section{Determinants of cardiac adaptation to exercise in female athletes}

The determinants of sex differences in physiological cardiac adaptation to exercise are not fully understood. However, hormonal, molecular, and genetic mechanisms are thought to be involved.

\section{Hormonal mechanisms}

Testosterone and its metabolite dihydrotestosterone act directly on cardiac myocytes stimulating myocardial hypertrophy $[34,35]$. Conversely, estrogens inhibit myocardial hypertrophy and the proliferation of cardiac fibroblasts. The myocardial response to these hormones does not solely depend on the circulating hormonal levels but also on their binding to cardiac receptors. Myocytes contain androgenic and estrogenic receptors, which seem to modulate the expression of specific cardiac genes with possible effects on sarcomeric proteins $[36,37]$. Moreover, estrogens increase nitric oxide level promoting peripheral vasodilatation and afterload reduction, and estrogens and testosterone have opposite effects on circulating levels of angiotensin converting enzyme activity promoting, respectively, peripheral vasodilation and vasoconstriction with different effects on blood pressure [38-40].

Cardiac remodeling is modulated by multiple signaling pathways which involve enzymatic regulation and cellular response. The energy substrate 
availability which depends on fatty acid oxidation and glucose uptake seems to influence physiological cardiac hypertrophy. Some enzymes involved in this process, as protein kinase B (AKT) and glycogen synthase kinase-3-beta (GSK 3 ), prevent the development of cardiac hypertrophy and their activity is reported to be higher in females $[41,42]$. Although these findings derive mainly from experimental models, with lack of data in humans, they could explain, at least in part, sex differences in cardiac remodeling.

Genetic mechanisms

A significant variability characterizes genes encoding for protein components of the renin-angiotensin system [43]. Studies on athletes showed a significant association between specific polymorphisms in the gene encoding for angiotensin and degree of LVH induced by endurance training. Sex is supposed to have an important role on the prevalence and expression of these polymorphisms possibly explaining the differences in cardiac adaptation to exercise [44, 45].

\section{Sudden cardiac death in female athletes}

Sudden cardiac death (SCD) is ten-fold less common among competitive female athletes in comparison with male counterparts [46, 47].

The commonest cause of SCD in older athletes ( $>35$ years) is atherosclerotic coronary artery disease (CAD), whereas in young athletes $(<35$ years), inherited cardiac diseases, such as cardiomyopathies and channelopathies, predominate [46]. Recent studies suggest that the most common finding at autopsy in young athletes who died suddenly is a structurally normal heart (sudden arrhythmic death syndrome or SADS), where primary arrhythmia syndromes as long QT syndrome, Brugada syndrome, and cathecolaminergic polymorphic ventricular tachycardia (CPVT) are the probable culprits $[48,49]$.

The higher prevalence of SCD in males was previously explained with the higher proportion of male athletes participating in competitive sports. However, the increasing participation of women in the recent years was not paralleled with an increase of SCD incidence in female athletes.

Various theories to explain the higher incidence of SCD in male athletes have been proposed. Sympathetic tone and increased catecholamines may trigger malignant arrhythmias in individuals with preexisting cardiac disease and males appear to have a higher sympathetic tone than females with possible deleterious effects in predisposed individuals $[16,50,51]$.

Sex hormones affect the regulation of cardiac repolarization, with effects on the QT interval with possible development of electrical instability and arrhythmias $[52,53]$. While androgens may have a role in the development of $\mathrm{LVH}$, estrogens may delay the phenotype expression in HCM, which may manifest later in women [54-56], and although both HCM and ARVC are transmitted as Mendelian autosomal dominant trait, their prevalence is higher in males $[28,54]$. The interplay between genetic and environmental factors in 
the development of cardiomyopathies, which are important causes of SCD especially in young athletes, is complex and not completely understood.

\section{Veteran female athletes}

Regular exercise has several beneficial effects for human health, decreases morbidity, and improves survival. Increasing numbers of athletes are able to continue their athletic activities into middle and even old age, participating at high-level athletic activity for many decades. Recent studies postulated a deleterious effects of high-intensity long-term exercise, which has been associated with greater prevalence of atrial fibrillation (AF), ventricular arrhythmias, coronary artery calcification (CAC), and myocardial fibrosis in veteran athletes $[57,58 \bullet \bullet]$. Most of these studies investigated the effects of long-term training in veteran male athletes, and to date, few studies included female athletes.

\section{Atrial fibrillation}

A higher prevalence of atrial fibrillation (AF) in athletes compared with sedentary counterparts has been recently demonstrated [59]. A recent meta-analysis on the topic reported a prevalence of male athletes in studies where an association between $\mathrm{AF}$ and sport was demonstrated [60].

The Women's Health Study, which enrolled middle-age healthy women, showed that while a moderate amount of physical activity is associated with lower prevalence of $\mathrm{AF}$, vigorous exercise regimens may increase this risk of developing AF [61]. However, female athletes exhibit a less pronounced atrial remodeling than male athletes, and larger atria are more susceptible to micro re-entries favored by the increase in adrenergic tone suggesting a possible lower risk of developing AF in women [62]. Although data on large cohort of male athletes suggest a 5-fold risk of developing $\mathrm{AF}$, studies on female athletes are on small samples, leaving questions on the prevalence of $\mathrm{AF}$ in this specific group of individuals still un-answered.

A possible role of long-term strenuous exercise in the development of coronary atherosclerosis has been recently shown in veteran athletes [6365]. A study comparing veteran endurance athletes with low atherosclerotic risk profile and sedentary controls showed a higher prevalence of significant coronary plaques and higher values of CAC in male athletes [58 $\bullet$ ]. Female athletes constituted only $30 \%$ of the overall population, and the prevalence of CAD or CAC score was similar in comparison with female controls. A comparison between sedentary middle-age women and women of similar age engaging in marathon running demonstrated a lower prevalence of coronary plaques and less calcified plaques in athletes, suggesting that the possible effects of long-term intense athletic training on coronary atherosclerosis may be different in men and women 
[66•]. Further studies on larger cohorts are needed to clarify if female veteran athletes are less likely to develop coronary atherosclerosis.

\section{Myocardial fibrosis}

Recent studies using cardiac magnetic resonance (CMR) showed a higher prevalence of late gadolinium enhancement (LGE) in marathon and ultramarathon runners compared with age-matched veteran controls [67, 68]. A correlation between the duration of training or number of marathons completed and the presence of myocardial fibrosis was reported. It is possible that repeated bouts of myocardial inflammation due to intense exercise lead to a permanent damage, which may result in arrhythmias [69, 70]. The LGE pattern is usually non-ischemic indicating that myocardial fibrosis is not related to CAD.

Again, most of the studies have included male athletes. A recent study reported on male and female triathletes who were investigated with CMR showing that LGE was present in $17 \%$ of males, but in none of the females [71]. Interestingly, athletes showing LGE were characterized by higher systolic blood pressure at peak exercise and increased LV mass index than athletes without LGE at CMR, and the systolic blood pressure at peak exercise was independently associated with myocardial fibrosis. It is possible that, as female athletes exhibit lower values of blood pressure at rest and during exercise, they are less prone to develop myocardial fibrosis. Myocardial fibrosis may constitute a substrate for potentially fatal arrhythmias and SCD, and its lower prevalence in female athletes may explain the lower incidence of SCD.

\section{Conclusion and future perspectives}

Long-term training results in a plethora of electrical, structural, and functional cardiac changes. Patterns of electrical and structural remodeling differ significantly between male and female athletes. While male athletes tend to exhibit more frequently voltage criteria for $\mathrm{LVH}$ and RVH at the ECG, in female athletes, anterior TWI is more common. Absolute cardiac dimensions are higher in male athletes, and female athletes rarely exhibit an enlarged LV raising the suspicion of DCM or LV wall thickness consistent with HCM. Endurance female athletes appear to adapt primarily by increasing ventricular dimensions as opposed to an increase in LV wall thickness. Finally, female athletes are less prone to sudden cardiac death and show less frequently coronary calcification, atrial fibrillation, and myocardial fibrosis in comparison with male counterparts.

Undoubtedly, males and females exhibit many biological, anatomical, and hormonal differences, and cardiac adaptation to exercise is no exception. The increasing participation of women in sports should stimulate the scientific community to develop large and longitudinal studies aimed at a better understanding of cardiac adaptation to exercise in female athletes. 


\section{What we know about...}

\section{ECG findings}

- Anterior TWI is more common in female than male athletes.

- Voltage criteria for LVH and RVH are less frequent in female athletes.

\section{Echocardiogram findings}

- Female endurance athletes tend to develop eccentric hypertrophy.

- $\mathrm{LVH}>13 \mathrm{~mm}, \mathrm{RWT}>0.48$, or $\mathrm{LVM}>145 \mathrm{~g} / \mathrm{m}^{2}$ in female athletes is suggestive of pathology.

- RV enlargement is common in female athletes.

\section{Clinical evolution}

- Veteran female athletes show less coronary artery calcification than males.

- Female athletes are less prone to SCD than males.

\section{What we believe...}

- Sex hormones and genetic factors play a role in cardiac remodeling.

- A better understanding of the mechanisms involved in cardiac adaptation to exercise in males and females may be useful to prevent SCD.

\section{Compliance with Ethical Standards}

\section{Conflict of Interest}

The authors declare that they have no conflicts of interest.

Human and Animal Rights and Informed Consent

This article does not contain any studies with human or animal subjects performed by any of the authors.

\section{Open Access}

This article is distributed under the terms of the Creative Commons Attribution 4.0 International License (http://creativecommons.org/licenses/by/4.0/), which permits unrestricted use, distribution, and reproduction in any medium, provided you give appropriate credit to the original author(s) and the source, provide a link to the Creative Commons license, and indicate if changes were made. 


\section{References and Recommended Reading}

Papers of particular interest, published recently, have been highlighted as:

- Of importance

$\bullet \quad$ Of major importance

1. Gati S, Sharma S. The athlete's heart. Br J Hosp Med. 2011;72(5):275-81.

2. Gialouris N, Andronikos MKI, et al. Olympic games in ancient Greece. Athens: Ekdotike Athenon; 1976.

3. Roberts WO, Roberts DM, Lunos S. Marathon related cardiac arrest risk differences in men and women. $\mathrm{Br} J$ Sports Med. 2013;47(3):168-71. https://doi.org/10. 1136/bjsports-2012-091119.

4. Word Olympians Association. [Internet]. Available from: https://olympians.org/news/675/olympic-movementcomes-together-at-olympians-reunion-centre-by-ey-inrio-to-honour-women-in-sport/ in 11/08/2016.

5. Malhotra A, Dhutia H, Gati S, Yeo T-J, Dores H, Bastiaenen $\mathrm{R}$, et al. Anterior T-wave inversion in young white athletes and nonathletes. J Am Coll Cardiol. 2017;69(1):1-9 Novel data on athlete's ECG (including females).

6.• Finocchiaro G, Dhutia H, D'Silva A, Malhotra A, Steriotis A, Millar L, et al. Effect of sex and sporting discipline on LV adaptation to exercise. JACC Cardiovasc Imaging. 2017;10(9):965-7.

Concept of left ventricular geometry with relevant information about $\mathrm{LV}$ remodelling in female athletes.

7. Corrado D, Basso C, Rizzoli G, Schiavon M, Thiene G. Does sports activity enhance the risk of sudden death in adolescents and young adults? J Am Coll Cardiol. 2003;42(11):1959-63. https://doi.org/10.1016/j.jacc. 2003.03.002.

8. Wilson M, Drezner J, Sharma S. International Olympic Committee - manual of sports cardiology, 1st edn. Wiley-Blackwell; 2016.

9. Pelliccia A, Culasso F, Di Paolo FM, Maron BJ. Physiologic left ventricular cavity dilation in elite athletes. Ann Intern Med. 1999;130(1):23-31.

10. Pelliccia A, Maron BJ, Spataro A, Proschan MA, Spirito $P$. The upper limit of physiologic cardiac hypertrophy in highly trained elite athletes. N Engl J Med. 1991;324(5):295-301. https://doi.org/10.1056/ NEJM199101313240504.

11. Basavarajaiah S, Boraita A, Whyte G, Wilson M, Carby $\mathrm{L}$, Shah A, et al. Ethnic differences in left ventricular remodeling in highly-trained athletes. Relevance to differentiating physiologic left ventricular hypertrophy from hypertrophic cardiomyopathy. J Am Coll Cardiol. 2008;51(23):2256-62.

12. Abergel E, Chatellier G, Hagege AA, Oblak A, Linhart A, Ducardonnet A, et al. Serial left ventricular adaptations in world-class professional cyclists: implications for disease screening and follow-up. J Am Coll Cardiol. 2004;44(1):144-9.

13. Abernethy WB, Choo JK, Hutter AM. Echocardiographic characteristics of professional football players. J
Am Coll Cardiol. 2003;41(2):280-4. https://doi.org/ 10.1016/S0735-1097(02)02633-5.

14. Zaidi A, Ghani S, Sharma R, Oxborough D, Panoulas VF, Sheikh N, et al. Physiological right ventricular adaptation in elite athletes of African and afro-caribbean origin. Circulation. 2013;127(17):1783-92.

15. Finocchiaro G, Sharma S. Do endurance sports affect female hearts differently to male hearts? Futur Cardiol. 2016;12(2):105-8. https://doi.org/10.2217/fca.15.85.

16. Schäfer D, Gjerdalen GF, Solberg EE, Khokhlova M, Badtieva V, Herzig D, et al. Sex differences in heart rate variability: a longitudinal study in international elite cross-country skiers. Eur J Appl Physiol. 2015;115(10):2107-14.

17. Wheatley CM, Snyder EM, Johnson BD, Olson TP. Sex differences in cardiovascular function during submaximal exercise in humans. Springerplus. 2014;3:445 Available from: http://www.ncbi.nlm.nih.gov/ pubmed/25191635.

18. Sharma S, Drezner JA, Baggish A, Papadakis M, Wilson MG, Prutkin JM, et al. International Recommendations for Electrocardiographic Interpretation in Athletes. J Am Coll Cardiol. 2017;69(8):1057-7.

Most recent and comprehensive references on the interpretation of the ECG in athletes.

19. Calore C, Zorzi A, Sheikh N, Nese A, Facci M, Malhotra $\mathrm{A}$, et al. Electrocardiographic anterior T-wave inversion in athletes of different ethnicities: differential diagnosis between athlete's heart and cardiomyopathy. Eur Heart J. 2016;37(32):2515-27.

20. Finocchiaro G, Papadakis M, Dhutia H, Zaidi A, Malhotra A, Fabi E, et al. Electrocardiographic differentiation between 'benign $\mathrm{T}$-wave inversion ' and arrhythmogenic right ventricular cardiomyopathy. 2018;(September):1-7.

21. Rawlins J, Carre F, Kervio G, Papadakis M, Chandra N, Edwards C, et al. Ethnic differences in physiological cardiac adaptation to intense physical exercise in highly trained female athletes. Circulation. 2010;121(9):1078-85. https://doi.org/10.1161/ CIRCULATIONAHA.109.917211.

22. Pelliccia A, Maron BJ, Culasso F, Spataro A, Caselli G. Athlete's heart in women. Echocardiographic characterization of highly trained elite female athletes. JAMA. 1996;276(3):211-5. https://doi.org/10.1001/jama. 1996.03540030045030.

23. D'Ascenzi F, Pisicchio C, Caselli S, Di Paolo FM, Spataro A, Pelliccia A. RV remodeling in Olympic athletes. JACC Cardiovasc Imaging. 2017;10(4):385-93. https://doi.org/10.1016/j.jcmg.2016.03.017.

24. D'Ascenzi F, Pelliccia A, Solari M, Piu P, Loiacono F, Anselmi F, et al. Normative Reference Values of Right 
Heart in Competitive Athletes: A Systematic Review and Meta-Analysis. J Am Soc Echocardiogr. 2017;30(9):845858.e2. https://doi.org/10.1016/j.echo.2017.06.013.

25. James CA, Bhonsale A, Tichnell C, Murray B, Russell $\mathrm{SD}$, Tandri $\mathrm{H}$, et al. Exercise increases age-related penetrance and arrhythmic risk in Arrhythmogenic right ventricular dysplasia/cardiomyopathy associated Desmosomal mutation carriers. J Am Coll Cardiol. 2013;62(14):1-19.

26. Saberniak J, Hasselberg NE, Borgquist R, Platonov PG, Sarvari SI, Smith H, et al. Vigorous physical activity impairs myocardial function in patients with arrhythmogenic right ventricular cardiomyopathy and in mutation positive family members. Eur J Heart Fail. 2014;16(12):1337-44. Doi.wiley.com. https://doi. org/10.1002/ejhf.181.

27. La Gerche A, Burns AT, Mooney DJ, Inder WJ, Taylor AJ, Bogaert J, et al. Exercise-induced right ventricular dysfunction and structural remodelling in endurance athletes. Eur Heart J. 2012;33(8):998-1006. https://doi. org/10.1093/eurheartj/ehr397.

28. Thiene G, Basso C. Arrhythmogenic right ventricular cardiomyopathy: an update. Cardiovasc Pathol. 2001;10(3):109-17 Available from: http://www.ncbi. nlm.nih.gov/pubmed/19362677.

29. Marcus FI, Mckenna WJ, Sherrill D, Basso C, Bauce B, Bluemke DA, et al. Diagnosis of Arrhythmogenic right ventricular cardiomyopathy / dysplasia proposed modification of the task force criteria. Circulation. 2010;121:1533-41.

30. Iskandar A, Mujtaba MT, Thompson PD. Left Atrium Size in Elite Athletes. JACC Cardiovasc Imaging. 2015;8(7):753-62. https://doi.org/10.1016/j.jcmg. 2014.12.032.

31. Sanchis L, Sanz-de La Garza M, Bijnens B, Giraldeau G, Grazioli G, Marin J, et al. Gender influence on the adaptation of atrial performance to training. Eur J Sport Sci. 2017;17(6):720-6. https://doi.org/10.1080/ 17461391.2017.1294620.

32. D'Ascenzi F, Pelliccia A, Natali BM, Zaca V, Cameli M, Alvino F, et al. Morphological and Functional Adaptation of Left and Right Atria Induced by Training in Highly Trained Female Athletes. Circ Cardiovasc Imaging. 2014;7(2):222-9. https://doi.org/10.1161/ CIRCIMAGING.113.001345.

33. Gabrielli L, Bijnens BH, Butakoff C, Duchateau N, Montserrat S, Merino B, et al. Atrial functional and geometrical remodeling in highly trained male athletes: for better or worse? Eur J Appl Physiol. 2014;114(6):1143-52.

34. Marsh JD, Lehmann MH, Ritchie RH, Gwathmey JK, Green GE, Schiebinger RJ. Androgen receptors mediate hypertrophy in cardiac myocytes. Circulation. 1998;98(3):256-61. https://doi.org/10.1161/01.CIR. 98.3.256

35. Zwadlo C, Schmidtmann E, Szaroszyk M, Kattih B, Froese N, Hinz H, et al. Antiandrogenic therapy with finasteride attenuates cardiac hypertrophy and left ventricular dysfunction. Circulation.
2015;131(12):1071-81. https://doi.org/10.1161/ CIRCULATIONAHA.114.012066.

36. Grohé C, Kahlert S, Löbbert K, Stimpel M, Karas RH, Vetter $\mathrm{H}$, et al. Cardiac myocytes and fibroblasts contain functional estrogen receptors 1 . FEBS Lett. 1997;416(1):107-12. https://doi.org/10.1016/S00145793(97)01179-4.

37. Morano I, Gerstner J, Ruegg JC, Ganten U, Ganten D, Vosberg HP. Regulation of myosin heavy chain expression in the hearts of hypertensive rats by testosterone. Circ Res. 1990;66(6):1585-90.

38. van Eickels M, Grohé C, JPM C, Janssen BJ, HJJ W, et al. 17beta-estradiol attenuates the development of pressure-overload hypertrophy. Circulation. 2001;104:1419-23.

39. Vega RB, Konhilas JP, Kelly DP, Leinwand LA. Molecular mechanisms underlying cardiac adaptation to exercise. Cell Metab. 2017;25(5):1012-26. https://doi. org/10.1016/j.cmet.2017.04.025.

40. Cavasin MA, Sankey SS, Yu A-L, Menon S, Yang X-P. Estrogen and testosterone have opposing effects on chronic cardiac remodeling and function in mice with myocardial infarction. Am J Physiol Circ Physiol. 2003;284(5):H1560-9. https://doi.org/10.1152/ ajpheart.01087.2002.

41. Foryst-Ludwig A, Kreissl MC, Sprang C, Thalke B, Böhm C, Benz V, et al. Sex differences in physiological cardiac hypertrophy are associated with exercise-mediated changes in energy substrate availability. Am J Physiol Heart Circ Physiol. 2011;301(1):H115-22. https://doi.org/10.1152/ ajpheart.01222.2010.

42. Foryst-Ludwig A, Kintscher U. Sex differences in exercise-induced cardiac hypertrophy. Pflugers Arch Eur J Physiol. 2013;465(5):731-7. https://doi.org/10. 1007/s00424-013-1225-0.

43. Corvol P, Jeunemaitre X. Molecular Genetics of Human Hypertension: Role of Angiotensinogen 1. Endocr Rev. 1997;18(5):662-77. https://doi.org/10.1210/ edrv.18.5.0312.

44. Diet F, Graf C, Mahnke N, Wassmer G, Predel HG, Palma-Hohmann I, et al. ACE and angiotensinogen gene genotypes and left ventricular mass in athletes. Eur J Clin Investig. 2001;31(10):836-42. https://doi. org/10.1046/j.1365-2362.2001.00886.x.

45. Karjalainen J, Kujala UM, Stolt A, Mäntysaari M, Viitasalo M, Kainulainen K, et al. Angiotensinogen gene M235T polymorphism predicts left ventricular hypertrophy in endurance athletes. J Am Coll Cardiol. 1999;34(2):494-9.

46. Maron BJ, Doerer JJ, Haas TS, Tierney DM, Mueller FO. Sudden deaths in young competitive athletes analysis of 1866 deaths in the united states, 1980-2006. Circulation. 2009;119(8):1085-92.

47. Marijon E, Tafflet M, Celermajer DS, Dumas F, Perier M-C, Mustafic H, et al. Sports-related sudden death in the general population. Circulation.

2011;124(6):672-81. https://doi.org/10.1161/ CIRCULATIONAHA.110.008979. 
48. Finocchiaro G, Papadakis M, Robertus J-L, Dhutia H, Steriotis AK, Tome M, et al. Etiology of sudden death in sports. J Am Coll Cardiol. 2016;67(18):2108-15.

49. Asif IM, Harmon KG. Incidence and etiology of sudden cardiac death: new updates for athletic departments. Sports Health. 2017;9(3):268-79. https://doi.org/10. $1177 / 1941738117694153$.

50. Iellamo F, Legramante MJ, Pigozzi F, Spataro A, Norbiato G, Lucini D, et al. Conversion from vagal to sympathetic predominance with strenuous training in high-performance world class athletes. Circulation. 2002;105(23):2719-24. https://doi.org/10.1161/01. CIR.0000018124.01299.AE.

51. Hedelin R, Wiklund U, Bjerle P, Henriksson-Larsen K. Pre- and post-season heart rate variability in adolescent cross-country skiers. Scand J Med Sci Sport.

2000;10(5):298-303. https://doi.org/10.1034/j.16000838.2000.010005298.x.

52. Rautaharju PM, Zhou S, Wong S, Calhoun H, Berenson GPR. Sex differences in the evolution of the electrocardiographic QT interval with age. Can J Cardiol. 1992;8:690-5.

53. Drici MD, Burklow TR, Haridasse V, Glazer RI, Woosley RL. Sex hormones prolong the QT interval and downregulate Potassium Channel expression in the rabbit heart. Circulation. 1996;94(6):1471-4. https://doi. org/10.1161/01.CIR.94.6.1471.

54. Olivotto I, Maron MS, Adabag AS, Casey SA, Vargiu D, Link MS, et al. Gender-related differences in the clinical presentation and outcome of hypertrophic cardiomyopathy. J Am Coll Cardiol. 2005;46(3):480-7. https:// doi.org/10.1016/j.jacc.2005.04.043.

55. Hagege AA, Schwartz K, Desnos M CL. Genetic basis and genotype-phenotype relationships in familial hypertrophic cardiomyopathy. In: Maron BJ MM, editor. Diagnosis and Management of Hypertrophic Cardiomyopathy. Blackwell Futura; 2014. p. 67-80.

56. Vikstrom KL, Factor SM, Leinwand LA. Mice expressing mutant myosin heavy chains are a model for familial hypertrophic cardiomyopathy. Mol Med. 1996;2(5):556-67.

57. Andersen K, Farahmand B, Ahlbom A, Held C, Ljunghall S, Michaëlsson K, et al. Risk of arrhythmias in 52755 long-distance cross-country skiers: a cohort study. Eur Heart J. 2013;34(47):3624-31. https://doi. org/10.1093/eurheartj/eht188.

58.• Merghani A, Maestrini V, Rosmini S, Cox AT, Dhutia H, Bastiaenan R, et al. Prevalence of subclinical coronary artery disease in masters endurance athletes with a low atherosclerotic risk profile clinical perspective. Circulation. 2017;136(2):126-37. https://doi.org/10.1161/ CIRCULATIONAHA.116.026964Novel data on the potentialy deleterious effect of lifelong exercise effect on the heart including female athletes.

59. Karjalainen J, Kujala UM, Kaprio J, Sarna S, Viitasalo M. Lone atrial fibrillation in vigorously exercising middle aged men: case-control study. BMJ.

1998;316(7147):1784-5. https://doi.org/10.1136/ bmj.316.7147.1784.
60. Abdulla J, Nielsen JR. Is the risk of atrial fibrillation higher in athletes than in the general population? A systematic review and meta-analysis. Europace. 2009;11(9):1156-9. https://doi.org/10.1093/ europace/eup197.

61. Everett BM, Conen D, Buring JE, Moorthy MV, Lee I-M, Albert CM. Physical activity and the risk of incident atrial fibrillation in women. Circ Cardiovasc Qual Outcomes. 2011;4(3):321-7. https://doi.org/10.1161/ CIRCOUTCOMES.110.951442.

62. Wilhelm M, Roten L, Tanner H, Wilhelm I, Schmid J-P, Saner H. Gender differences of atrial and ventricular remodeling and autonomic tone in nonelite athletes. Am J Cardiol. 2011;108(10):1489-95.

63. Mohlenkamp S, Lehmann N, Breuckmann F, BrockerPreuss M, Nassenstein K, Halle M, et al. Running: the risk of coronary events : prevalence and prognostic relevance of coronary atherosclerosis in marathon runners. Eur Heart J. 2008;29(15):1903-10. https:// doi.org/10.1093/eurheartj/ehn163.

64. Aengevaeren VL, Mosterd A, Braber TL, Prakken NHJ, Doevendans PA, Grobbee DE, et al. Relationship between lifelong exercise volume and coronary atherosclerosis in athletes. Circulation. 2017;136(2):138-48. https://doi. org/10.1161/CIRCULATIONAHA.117.027834.

65. Baggish AL, Levine BD. Coronary artery calcification among endurance athletes. Circulation. 2017;136(2):149-51. https://doi.org/10.1161/ CIRCULATIONAHA.117.028750.

66. Roberts WO, Schwartz RS, Kraus SM, Schwartz JG, Peichel $\mathrm{G}$, Garberich RF, et al. Long-term Marathon running is associated with low coronary plaque formation in women. Med Sci Sport Exerc. 2017;49(4):641-.

Novel data on CAC in women marathon runners.

67. Wilson M, O'Hanlon R, Prasad S, Deighan A, MacMillan $\mathrm{P}$, Oxborough D, et al. Diverse patterns of myocardial fibrosis in lifelong, veteran endurance athletes. J Appl Physiol. 2011;110(6):1622-6. https://doi.org/10. 1152/japplphysiol.01280.2010.

68. Breuckmann F, Möhlenkamp S, Nassenstein K, Lehmann N, Ladd S, Schmermund A, et al. Myocardial late gadolinium enhancement: prevalence, pattern, and prognostic relevance in Marathon runners. Radiology. 2009;251(1):50-7. https://doi.org/10.1148/radiol. 2511081118.

69. La Gerche A. Can intense endurance exercise cause myocardial damage and fibrosis? Curr Sports Med Rep. 2013;12(2):63-9.

70. Baggish AL. Focal fibrosis in the endurance Athlete's heart. JACC Cardiovasc Imaging. 2017;11:1271-3. https://doi.org/10.1016/j.jcmg.2017.09.015.

71. Tahir E, Starekova J, Muellerleile K, von Stritzky A, Münch J, Avanesov M, et al. Myocardial Fibrosis in Competitive Triathletes Detected by ContrastEnhanced CMR Correlates With Exercise-Induced Hypertension and Competition History. JACC Cardiovasc Imaging. 2017. https://doi.org/10.1016/j.jcmg.2017. 09.016 . 